\title{
The emerging public-health science of sedentary time: what is the relevance to low and middle income countries?
}

Rev Bras Ativ Fis Saúde p. 457-460

DOI: http://dx.doi.org/10.12820/2317.

1634.2012v17n6p457

1 Baker IDI Heart and Diabetes Institute, Melbourne, Australia; Melbourne, Monash and Queensland Universities

Neville Owen ${ }^{1}$

With economic development and urbanization, the life settings and behavioural choices of people in low and middle income countries are changing and doing so in a plethora of ways that can be important determinants of their health outcomes. Reduced levels of physical activity, changes from traditional eating patterns to the consumption of manufactured foods and Westernised diets, with consequent weight gain - metabolically-toxic market failures within economic development - are associated with increased risk of type 2 diabetes, cardiovascular disease and breast and colon cancer; and, will result in unaffordable future health-care costs. In this context, too much sitting is emerging as a preventive-health concern.

\section{SEDENTARY VERSUS PHYSICALLY-ACTIVE TIME}

For health-related physical activity, we typically consider moderate-to-vigorous activity (MVPA) such as bicycling, swimming, walking, or running, which require an energy expenditure of 3 to $8 \mathrm{MET}$ (METs are, broadly speaking, multiples of the basal metabolic rate - energy expenditure at rest). Light intensity activity activities are behaviours typically done while standing, requiring expenditure of no more than 2.9 METS. The other broad class of determinant of energy expenditure during waking hours involves sedentary behaviours (from the Latin sedere, 'to sit') - sitting during commuting, in the workplace and the domestic environment, and during leisure time. ${ }^{1}$ Sedentary behaviours are in the energy-expenditure range of 1.0 to 1.5 METs. The Sedentary Behaviour Research Network defines this as any behaviour during waking hours that is characterized by energy expenditure greater than or equal to $1.5 \mathrm{MET}$, while in a sitting or reclining posture; the term "inactive" should thus be used to describe those who are performing insufficient amounts of MVPA (i.e., not meeting specified physical activity guidelines). ${ }^{2}$

\section{TOO MUCH SITTING AS A NEW PUBLIC HEALTH CONCERN}

Prolonged sitting is a health risk distinct from a lack of physical activity or exercise. Findings of the relevant large-scale epidemiological studies have been reviewed elsewhere. ${ }^{3-5}$ For example, in AusDiab (the Australian Diabetes, Obesity and Lifestyle Study - a large national survey on obesity, diabetes and risk factors among adults), high levels of TV viewing time were associated with having the metabolic syndrome and its components (abdominal obesity, in combination with indices of disordered glucose and lipid regulation), with abnormal glucose metabolism and with adverse levels of insulin and blood glucose; ${ }^{6-8}$ with continuous measures of metabolic syndrome components; ${ }^{9}$ and, with adverse retinal blood vessel indices associated with development of eye and broader systemic diseases. ${ }^{10}$ AusDiab 
participants who wore accelerometers - small electronic devices placed on the hip - for a week showed not only adverse associations of total sedentary time with risk biomarkers, but also a protective role for breaks in sedentary time. ${ }^{11}$ This influential 'breaks' finding has been confirmed using a large US population-based data set ${ }^{12}$ and in a laboratory experimental model..$^{13}$. Mortality outcomes from AusDiab and their implications have also been examined. Six years following the AusDiab baseline assessment, those with higher levels of television viewing time had an increased risk of premature death from all causes and from cardiovascular disease. ${ }^{14}$ It was estimated that for every one hour of television viewing after 25 years of age, there is a 22 minute reduction in life expectancy - an effect that is comparable to the estimated impact of obesity on population health. ${ }^{15}$

\section{ADULTS CAN SIT FOR PROLONGED PERIODS OF TIME}

Recent studies that have employed objective measures of all movement during every minute of waking hours (using accelerometers) have shown that typical adults in the USA and Australia, for example, on average only engage in around 20-30 min of moderate-to-vigorous physical activity, can have up to 10 hours of sedentary (sitting) time and spend the balance of their waking hours in light-intensity activity. ${ }^{16}$ Time spent sitting displaces time spent in higher-intensity physical activities - thereby contributing to a reduction in overall energy expenditure. For example, replacing two hours of sitting time with light-intensity activity ( 2 hours * (2.5 METs - 1.5 METs) = 2.0 MET-hours) would exceed the additional energy-expenditure associated with $30 \mathrm{~min}$ of walking that would displace either sitting-time ( 0.5 hours * (3.5 METs $-1.5 \mathrm{METs})=1.0 \mathrm{MET}$-hours $)$ or light intensity-time (0.5 hours * (3.5 METs - 2.5 METs) = 0.5 MET-hours). Thus, two additional hours of sitting each day, in simple energy-expenditure terms, would negate what is achieved by meeting the basic physical activity and health recommendation through walking.

\section{SEDENTARY TIME VARIES SIGNIFICANTLY BETWEEN COUNTRIES}

Bauman and colleagues ${ }^{17}$ have recently reported a study of sitting time in 20 countries. Countries in which adults reported the lowest amount of sitting included Portugal, Brazil, and Colombia (medians of $180 \mathrm{~min} /$ day), whereas respondents from Taiwan, Norway, Hong Kong, Saudi Arabia and Japan reported the highest sitting times (medians of $360 \mathrm{~min} /$ day). This two-fold variation between countries in what are already high volumes of total sitting time is likely attributable to multiple factors that vary between countries, which might include built-environment attributes; work, family and other social arrangements; cultural practices and preferences; and, other factors. There is some preliminary evidence that the relationships of built environment attributes with sedentary behaviour have consistencies and differences between countries. ${ }^{18}$

\section{MULTI-COUNTRY INITIATIVES WILL BE CRUCIAL}

Multi-country research initiatives (including the International Physical Activity and the Environment Network project ${ }^{19}$ ) are now building methods to examine a broad-range of environmental variations that may determine physically-active and 
sedentary behaviours. With much of the research on environmental determinants of physical activity and sedentary behaviour having been conducted in the USA, Belgium and Australia, it has become clear that in order to understand how such determinants might operate and to inform the relevant environment and policy initiatives, data from a variety of international sources with broad social, environmental and culturally-related variations will be required. ${ }^{18,19}$ Important insights into the relevant environmental, economic, social and cultural variations and other factors influencing prolonged sitting time are likely to arise, particularly through findings from low and middle income countries where the population impacts of changes can be documented. These findings have important public-health implications.

\section{REFERENCES}

1. Sedentary Behaviour Research Network. Standardized use of the terms "sedentary" and "sedentary behaviours" Appl Physiol Nutr Metab. 2012;37:540-542.

2. Owen, N., Healy, G.N., Matthews, C. E. and Dunstan, D. W. (2010). Too much sitting: the population-health science of sedentary behavior. Exercise and Sports Sciences Reviews, 38, 105-113.

3. Hamilton MT, Healy GN, Dunstan DW, Zderic TW, Owen N. Too little exercise and too much sitting: Inactivity physiology and the need for new recommendations on sedentary behaviour. Curr Cardiovas Risk Rep. 2008;2(4):292-298.

4. Hamilton MT, Owen N. Sedentary behavior and inactivity physiology. In: Bouchard C, Blair SN, Haskell WL, eds. Physical Activity and Health. 2nd ed. Champaign, Illinois: Human Kinetics; 2012.

5. Thorp AA, Owen N, Neuhaus M, Dunstan DW. Sedentary behaviors and subsequent health outcomes in adults a systematic review of longitudinal studies, 1996-2011. Am J Prev Med. 2011;41(2):207-215.

6. Dunstan DW, Salmon J, Owen N, et al. Associations of TV viewing and physical activity with the metabolic syndrome in Australian adults. Diabetologia. 2005;48(11):2254-2261.

7. Dunstan DW, Salmon J, Owen N, et al. Physical activity and television viewing in relation to risk of undiagnosed abnormal glucose metabolism in adults. Diabetes Care. 2004;27(11):26032609.

8. Dunstan DW, Salmon J, Healy GN, et al. Association of television viewing with fasting and 2 -h postchallenge plasma glucose levels in adults without diagnosed diabetes. Diabetes Care. 2007;30(3):516-522.

9. Thorp AA, Healy GN, Owen N, et al. Deleterious associations of sitting time and television viewing time with cardiometabolic risk biomarkers: Australian Diabetes, Obesity and Lifestyle (AusDiab) study 2004-2005. Diabetes Care. 2010;33(2):327-334.

10. Anuradha S, Dunstan DW, Healy GN, et al. Physical activity, television viewing time, and retinal vascular caliber. Med Sci Sports Exerc. 2011;43(2):280-286.

11. Healy GN, Dunstan DW, Salmon J, et al. Breaks in sedentary time: beneficial associations with metabolic risk. Diabetes Care. 2008;31(4):661-666.

12. Healy GN, Matthews CE, Dunstan DW, Winkler EA, Owen N. Sedentary time and cardio-metabolic biomarkers in US adults: NHANES 2003-06. Eur Heart J. 2011;32(5):590-597.

13. Dunstan DW, Kingwell BA, Larsen R, et al. Breaking up prolonged sitting reduces postprandial glucose and insulin responses. Diabetes Care. 2012;35(5):976-983.

14. Dunstan DW, Barr EL, Healy GN, et al. Television viewing time and mortality: the Australian Diabetes, Obesity and Lifestyle Study (AusDiab). Circulation. 2010;121(3):384-391.

15. Veerman JL, Healy GN, Cobiac LJ, et al. Television viewing time and reduced life expectancy: a life table analysis. Br J Sports Med. 2012;46(13):927-930.

16. Owen N, Sparling PB, Healy GN, Dunstan DW, Matthews CE. Sedentary behavior: emerging evidence for a new health risk. Mayo Clin Proc. 2010;85(12):1138-1141.

17. Bauman A, Ainsworth BE, Sallis JF, et al. The descriptive epidemiology of sitting: a 20-country comparison using the International Physical Activity Questionnaire (IPAQ). Am J Prev Med 2011;41(2):228 -35. 
18. Owen N, Sugiyama T, Eakin EE, Gardiner PA, Tremblay MS, Sallis JF. Adults' sedentary behavior determinants and interventions. Am J Prev Med. 2011;41(2):189-196

19. Kerr, J., Sallis, J., Owen, N., De Bourdeaudhuij, I., Cerin, E., Reis, R., Sarmiento, O., Frömel, K., Mitáš, J., Troelsen, J., Christiansen, L., Macfarlane, D., Salvo, D., Schofield, G., Badland, H., Guillen-Grima, F., Aguinaga-Ontoso, I., Davey, R., Bauman, A., Saelens, B., Riddoch, C., Ainsworth, B., Pratt, M., Schmid, T., Frank, L., Adams, M., Conway, T., Cain, K., Van Dyck, D. and Bracy, N. Advancing Science and Policy through a Coordinated International Study of Physical Activity and Built Environments: IPEN Methods. Journal of Physical Activity and Health, (e-pub ahead of print September 11, 2012). 